\title{
Heterocyclization of Isoniazid: Synthesis and Antimicrobial Activity of Some New Pyrimidine, 1, 3-Thiazole, 1, 2, 4-Thiadiazole, and 1, 2, 4-Triazole Derivatives Derived from Isoniazid
}

\author{
Mona E. Farhan* and Mohammed G. Assy \\ Department of Chemistry, Faculty of Science, Zagazig University, Egypt.
}

$\mathbf{T}$

HE REACTION of isonicotinic hydrazide (1) (isoniazid) with cinnamoyl isothiocyanate (2) afforded cinnamoyl thiosemicarbazide derivative $\mathbf{3}$. Treatment of $\mathbf{3}$ with lead acetate in acetic acid, sodium ethoxide, sulphuric acid, chloroacetylchloride and sodium hypochlorite and sodium hydroxide gave the corresponding dihydropyrimidine $\mathbf{4}$, triazolethiazine $\mathbf{5}$, 1,3,4-thiadiazole $\mathbf{6}, 1,3$-thiazole $\mathbf{7}$ and 1,2,4-thiadiazole $\mathbf{8}$, respectively. The reactivity of isoniazid 1 towards ammonium thiocyanate, cyclohexanone and acetophenone to give 1,2,4-triazole thione 10, hydrazones $\mathbf{9}$ and $\mathbf{1 2}$ was studied. Treatment of hydrazones $\mathbf{9}$ and $\mathbf{1 2}$ with carbon disulfide and aryl isothiocyanates gave 1,3,4-thiadiazolidine $\mathbf{1 1}$ and 1,2,4-triazole thione derivatives 13a, b. The antimicrobial activity of these new compounds has been evaluated against 6 microbial strains. Some of the newly synthesized compounds showed moderate activity.

Keywords: Isonicotinichydrazide, Triazolothiazine, Thiadiazole, Triazolethione, Dihydropyrimidine, Thiazole, Antimicrobial activity.

\section{Introduction}

Isoniazid is a manufactured antimicrobial and a standout amongst the most vital first-line drugs utilized as a part of the treatment of tuberculosis (TB). Indeed, even after its discovery more than 60 years ago, the drug stays at the front line of the anti-tuberculosis treatment mainly due to its potency and high selectivity against Mycobacterium tuberculosis [1-4]. In 2016, the World Health Organization (WHO) announced that there were around 10.4 million new TB cases in worldwide with approximately 1.3 million TB deaths among HIV negative people and 0.374 million deaths among HIV-positive individuals[5-7]. Therefore, there is a critical need to synthesise new antitubercular drugs (ATDs), which will be powerful against all forms of TB, in all individuals and in all locations of the world.

A survey of literature reveals that the heterocyclic compounds that contain 1,2,4-triazole rings and 1,3,4-thiadiazole rings possess antimicrobial activity [8-11]. For instance, substituted 1,2,4-triazole ring such as vorozole and anastraole had been used in chemotherapy for treatment of breast cancer [12-15]. In light of above facts, The aim of the present work is to elucidate the chemistry of thiocarbamoyl derivatives $\mathbf{3}$, which prepared by the reaction of isonicotinic acid hydrazide $\mathbf{1}$ (Isoniazid) and cinnamoyl isothiocyanate $\mathbf{2}$, and also to study its importance as versatile reagent in the synthesis of such functionalized new heterocyclic compounds. This study reports on the synthesis of several new thiazole, thiadiazoles, triazoles, triazolothiazine and pyrimidine derivatives by the reaction of thiocarbomyl derivatives $\mathbf{3}$ with various reagents. These newly synthesized compounds have not been reported previously, and were prepared in good yields under very mild conditions.

\section{Experimental}

\section{Chemistry}

Melting points were measured using an Electrothermal IA 9100 apparatus with open capillary tube and are uncorrected. All experiments were carried out using drying solvents. Products were purified by recrystallization. The IR spectrum (KBr disc) was recorded on a Pye Unicam Sp3-300 or a Shimadzu FTIR 8101 PC infrared spectrophotometer. The ${ }^{1} \mathrm{H}$ NMR $400 \mathrm{MHz}$ and ${ }^{13} \mathrm{CNMR} 100 \mathrm{MHz}$ spectrum were measured on a JEOL-JNM-LA spectrometer using DMSO as a solvent. All chemical shifts were expressed on the $\delta$ (ppm) scale using TMS as an internal standard reference. The coupling constant $(J)$ values are given in $\mathrm{Hz}$. Analytical data were obtained from the Microanalysis Center at Cairo. The mass

*Corresponding author e-mail: monafarhan@zu.edu.eg DOI: 10.21608/EJCHEM.2018.4427.1393

(C)2017 National Information and Documentation Center (NIDOC) 
spectra were recorded on an MS-S988 instrument operating at $70 \mathrm{eV}$.

\section{$N$-(2-isonicotinoylhydrazinecarbonothioyl) cinnamamide (3)}

A mixture of cinnamoyl isothiocyanate $\mathbf{2}$ (18.92 $\mathrm{g}, 0.1 \mathrm{~mol})$ and isonicotinic acid hydrazide $1(13.71 \mathrm{~g}, 0.1 \mathrm{~mol})$ in dioxane $(50 \mathrm{~mL})$ was heated under reflux for $1 \mathrm{hr}$. The precipitate obtained after pouring onto water was crystallized from ethanol to give compound $\mathbf{3}$ as yellow powder. Yield 71\% m.p. $278-280{ }^{\circ} \mathrm{C}$. Elem. Anal. Calcd. (\%) for $\mathrm{C}_{16} \mathrm{H}_{14} \mathrm{~N}_{4} \mathrm{O}_{2} \mathrm{~S}$ (326.37): C, 58.88; H, 4.32; N, 17.17; S, 9.82. Found: C, 58.9; H, 4.40; N, 17.2; S, 9.83. IR (KBr, v, cm cm $^{-1} 3194(\mathrm{NH}), 2653$ $(\mathrm{SH}), 1686(\mathrm{C}=\mathrm{O}), 1668(\mathrm{C}=\mathrm{O}), 1631(\mathrm{C}=\mathrm{N})$, $1215(\mathrm{C}=\mathrm{S}) .{ }^{1} \mathrm{H}$ NMR (400 MHz, DMSO- $\left.d_{6}\right) \delta$ (ppm): 13.62 (br. s, 1H, SH), 12.26 (s, 1H, NH), 11.76 (s, 1H, NH), 11.42 (s, 1H, NH), 8.81- 8.77 (d, $1 \mathrm{H}, J=16 \mathrm{~Hz}, \mathrm{CH}=\mathrm{CH}), 8.70-7.48(\mathrm{~m}, 9 \mathrm{H}$, $\mathrm{CH}$ of phenyl ring and pyridine ring), 7.089-7.049 (d, $1 \mathrm{H}, J=16 \mathrm{~Hz}, \mathrm{CH}=\mathrm{CH}$ ).

$N$ - (4-oxo-6-phe nyl-2 - thioxo-3,4dihydropyrimidin-1(2H)-yl)isonicotinamide (4)

A mixture of compound $3(0.326 \mathrm{~g}, 1 \mathrm{mmol})$ and lead acetate $(0.321 \mathrm{~g}, 1 \mathrm{mmol})$, in acetic acid (30 $\mathrm{mL}$ )was refluxed for $2 \mathrm{hr}$ then the mixture was poured onto water and stirred for $15 \mathrm{~min}$. The white powder of compound $\mathbf{4}$ was obtained after recrystallization from acetic acid. Yield $66 \%$, m.p. 359-360 ${ }^{\circ} \mathrm{C}$. Elem. Anal. Calcd. (\%) for: $\mathrm{C}_{16} \mathrm{H}_{12} \mathrm{~N}_{4} \mathrm{O}_{2} \mathrm{~S}$ (324.07): C, 59.25; H, 3.73; N, 17.27; S, 9.89. Found: C, 59.30; H, 3.80; N, 17.30; S, 9.90. IR (KBr, v, cm $\left.{ }^{-1}\right): 3150(\mathrm{NH}), 1689$ $(\mathrm{C}=\mathrm{O}), 1634(\mathrm{C}=\mathrm{O}), 1217(\mathrm{C}=\mathrm{S}) .{ }^{1} \mathrm{HNMR}(400$ MHz, DMSO- $\left.d_{6}\right) \delta$ (ppm): 12.01 (br. s, $1 \mathrm{H}, \mathrm{NH}$ ), 12.00 (br. s, $1 \mathrm{H}, \mathrm{NH}), 8.75-8.74$ (d, $2 \mathrm{H}, J=4.8 \mathrm{~Hz}$, $\mathrm{CH}$ of $\mathrm{C}_{2}$ and $\mathrm{C}_{6}$ of pyridine ring), 7.94-7.93 (d, $2 \mathrm{H}, \mathrm{J}=4.8 \mathrm{~Hz}, \mathrm{CH}$ of $\mathrm{C}_{3}$ and $\mathrm{C}_{5}$ of pyridine ring), 7.85-6.95 (m, 6H, $\mathrm{CH}$ of phenyl ring, $\mathrm{CH}$ of pyrimidine ring). ${ }^{13} \mathrm{CNMR}\left(100 \mathrm{MHz}, \mathrm{DMSO}-d_{6}\right)$ $\delta$ (ppm): $172.06(\mathrm{C}=\mathrm{S}), 163.64(\mathrm{C}=\mathrm{O}), 160.00$ $(\mathrm{C}=\mathrm{O}), 150.74,143.72,137.16,134.03,130.68$, 129.142, 128.18, 120.80, 118.90 (Ar-C).

\section{7 - Phenyl-3 - (pyridin-4-yl) - $5 H$ - [1,2,4] triazolo[3,4-b][1,3]thiazin-5-one (5)}

A mixture of compound $3(0.326 \mathrm{~g}, 1 \mathrm{mmol})$ and sodium ethoxide $(0.015 \mathrm{~mol}$ in $30 \mathrm{~mL}$ ethanol) was heated under reflux for $2 \mathrm{hr}$. the content of flask was poured onto water to give a yellow powder that collected by filtration and recrystallized from acetic acid to give compound
5 as yellow powder. Yield $80 \%$, m.p. $358-360{ }^{\circ} \mathrm{C}$. Elem. Anal. Calcd. (\%) for $\mathrm{C}_{16} \mathrm{H}_{10} \mathrm{~N}_{4} \mathrm{OS}$ (306.34): C, 62.73; H, 3.29; N, 18.29; S, 10.47. Found: C, $62.8 ; \mathrm{H}, 3.3 ; \mathrm{N}, 18.3 ; \mathrm{S}, 10.5$. IR $\left(\mathrm{KBr}, \mathrm{v}, \mathrm{cm}^{-1}\right)$ : $1641(\mathrm{C}=\mathrm{O}), 1554 \quad(\mathrm{C}=\mathrm{N}) .{ }^{1} \mathrm{H}$ NMR $(400 \mathrm{MHz}$, DMSO- $\left.d_{6}\right) \delta(\mathrm{ppm}): 8.52-8.53(\mathrm{~d}, 2 \mathrm{H}, J=1.5$ $\mathrm{Hz}, \mathrm{CH}$ of $\mathrm{C}_{2}$ and $\mathrm{C}_{6}$ of pyridine ring), 8.51-8.52 (d, $2 \mathrm{H}, J=1.5 \mathrm{~Hz}, \mathrm{CH}$ of $\mathrm{C}_{3}$ and $\mathrm{C}_{5}$ of pyridine ring), 7.77-6.48 (m, $6 \mathrm{H}, \mathrm{CH}$ of phenyl ring, $\mathrm{CH}$ of thiazine ring). ${ }^{13} \mathrm{C}$ NMR (100 MHz, DMSO- $d_{6}$ ) $\delta$ (ppm): $172.55(\mathrm{C}=\mathrm{O}), 169.09,167.23,150.92$, $149.69,135.57,139.21,128.92,128.72,127.45$, 125.13, 119.48 (Ar-C).

\section{$N$-(5-(pyridin-4-yl)-1,3,4-thiadiazol-2-yl)} cinnamamide (6)

A solution of compound $3(1 \mathrm{mmol})$ and sulphuric acid $(5 \mathrm{~mL})$ in ethanol $(15 \mathrm{~mL}$ was refluxed for $2 \mathrm{hr}$. The precipitate was obtained after pouring onto water and recrystallized from acetic acid and to give compound $\mathbf{6}$ as a white powder. Yield $55 \%$, m.p. $338-340^{\circ} \mathrm{C}$. Elem. Anal. Calcd. (\%) for $\mathrm{C}_{16} \mathrm{H}_{12} \mathrm{~N}_{4} \mathrm{OS}$ (308.36): C, 62.32; H, 3.92; N, 18.17; S, 10.40. Found: C, 62.4; H, $3.93 ; \mathrm{N}, 18.2 ; \mathrm{S}, 11.0$. IR $\left(\mathrm{KBr}, \mathrm{v}, \mathrm{cm}^{-1}\right): 3431$ $(\mathrm{NH}), 1689(\mathrm{C}=\mathrm{O}), 1634(\mathrm{C}=\mathrm{N}) .{ }^{1} \mathrm{H}$ NMR (400 MHz, DMSO- $\left.d_{6}\right) \delta$ (ppm): 11.94 (br. s, $1 \mathrm{H}, \mathrm{NH}$ ), 8.75- $8.74\left(\mathrm{~d}, 2 \mathrm{H}, J=4 \mathrm{~Hz}, \mathrm{CH}\right.$ of $\mathrm{C}_{2}$ and $\mathrm{C}_{6}$ of pyridine ring), 7.94-7.93 (d, $2 \mathrm{H}, J=4 \mathrm{~Hz}, \mathrm{CH}$ of $\mathrm{C}_{3}$ and $\mathrm{C}_{5}$ of pyridine ring), 7.85-7.81 $(\mathrm{d}, 1 \mathrm{H}, \mathrm{J}=$ $16 \mathrm{~Hz}, \mathrm{CH}=\mathrm{CH}), 7.68-7.48(\mathrm{~m}, 5 \mathrm{H}, \mathrm{CH}$ of phenyl ring), 6.99-6.95 (d, $1 \mathrm{H}, J=16 \mathrm{~Hz}, \mathrm{CH}=\mathrm{CH}) .{ }^{13} \mathrm{C}$ NMR (100 MHz, DMSO- $\left.d_{6}\right) \delta(\mathrm{ppm}): 163.57$ $(\mathrm{C}=\mathrm{O}), 159.96(\mathrm{C}=\mathrm{N}), 159.89(\mathrm{C}=\mathrm{N}) 143.82$, $150.75,134.00,137.13,130.72,129.72,128.20$, 120.82, 118.78 (Ar-C and ethene-C) .

$N^{\prime}$-(3-cinnamoyl-4-hydroxythiazol-2(3H)ylidene)isonicotinohydrazide (7)

A mixture of compound 3 (1 mmol) and chloroacetylchloride in the presence of sodium acetate $(1 \mathrm{mmol})$, in dioxane $(15 \mathrm{~mL})$ was left at room temperature overnight, then the content of flask was poured onto water and stirred for $15 \mathrm{~min}$. The yellow powder of compound 7 was obtained after recrystallization from ethanol. Yield 54\%, m.p. $253-255^{\circ} \mathrm{C}$. Elem. Anal. Calcd. (\%) for $\mathrm{C}_{18} \mathrm{H}_{14} \mathrm{~N}_{4} \mathrm{O}_{3} \mathrm{~S}$ (366.39): C, 59.01; $\mathrm{H}, 3.85$; N, 15.29; S, 8.75. found: C, 60; H, 3.9; N, 15.3; $\mathrm{S}$, 8.8. IR $\left(\mathrm{KBr}, \mathrm{v}, \mathrm{cm}^{-1}\right): 3394(\mathrm{NH}), 1681(\mathrm{C}=\mathrm{O})$, $1627(\mathrm{C}=\mathrm{O}) .{ }^{1} \mathrm{H}$ NMR (400 MHz, DMSO-d $) \delta$ (ppm): 13.17 (s, 1H, OH), $12.93(\mathrm{~s}, 1 \mathrm{H}, \mathrm{NH})$, 8.81-8.79 (d, $2 \mathrm{H}, J=6 \mathrm{~Hz}, \mathrm{CH}$ of $\mathrm{C}_{2}$ and $\mathrm{C}_{6}$ of pyridine ring), 8.06-8.05 (d, $2 \mathrm{H}, J=6 \mathrm{~Hz}, \mathrm{CH}$ of $\mathrm{C}_{3}$ and $\mathrm{C}_{5}$ of pyridine ring), 7.87-7.83 (d, $1 \mathrm{H}, J=$ 
$15 \mathrm{~Hz}, \mathrm{CH}=\mathrm{CH}), 7.83-7.47$ (m, 5H, CH of phenyl ring), 6.99-6.95 (d, $1 \mathrm{H}, J=15 \mathrm{~Hz}, \mathrm{CH}=\mathrm{CH}), 5.18$ (s, $1 \mathrm{H}, \mathrm{CH}$ of thiazole ring). ${ }^{13} \mathrm{CNMR}(100 \mathrm{MHz}$, DMSO- $\left.d_{6}\right) \delta$ (ppm): $164.18(\mathrm{OH}-\mathrm{C}=), 164.06$ $(\mathrm{C}=\mathrm{O}), 161.10(\mathrm{C}=\mathrm{N}), 148.19,144.56,144.25$, 134.44, 134.39, 131.28, 131.17, 129.59, 119.18, 58.72(Ar-C, ethene- $\mathrm{C}$ and $-\mathrm{CH}=$ ).

$N^{\prime}-(3-((E)$-styryl)-1, 2, 4-thiadiazol-5(4H)ylidene) isonicotino hydrazide (8)

A solution of compound 3 (1 $\mathrm{mmol})$, sodium hypochlorite $(5 \mathrm{~mL})$, in the presence of $\mathrm{NH}_{4} \mathrm{OH}(10 \mathrm{~mL})$, and $\mathrm{NaOH}(5 \mathrm{~mL})$ was left at room temperature overnight, The precipitate was obtained after pouring onto water and recrystallized from ethanol and to give compound 8 as a yellow powder. Yield 45\%, m.p. 135-137 ${ }^{\circ} \mathrm{C}$. Elem. Anal. Calcd. (\%) for $\mathrm{C}_{16} \mathrm{H}_{13} \mathrm{~N}_{5} \mathrm{OS}$ (323.37): C, 59.43; H, 4.05; N, 21.66; S, 9.92. Found: C, 59.5; H, 4.1; N, 21.7; S, 10.1. IR $\left(\mathrm{KBr}, v, \mathrm{~cm}^{-1}\right): 3055(\mathrm{NH}), 1685(\mathrm{C}=\mathrm{O}), 1631$ $(\mathrm{C}=\mathrm{N}) .{ }^{1} \mathrm{HNMR}\left(400 \mathrm{MHz}, \mathrm{DMSO}-\mathrm{d}_{6}\right) \delta(\mathrm{ppm})$ : 12.41 (br. s, $2 \mathrm{H}, 2 \mathrm{NH}$ ), 7.70-7.69 (d, 2H, $J=3$ $\mathrm{Hz}, \mathrm{CH}$ of $\mathrm{C}_{2}$ and $\mathrm{C}_{6}$ of pyridine ring), 7.68-7.68 (d, $2 \mathrm{H}, J=3 \mathrm{~Hz}, \quad \mathrm{CH}$ of $\mathrm{C}_{3}$ and $\mathrm{C}_{5}$ of pyridine ring), 7.62-7.58 (d, $1 \mathrm{H}, J=16 \mathrm{~Hz}, \mathrm{CH}=\mathrm{CH})$, 7.43- $7.42(\mathrm{~m}, 5 \mathrm{H}, \mathrm{CH}$ of phenyl ring), 6.566.52(d, $1 \mathrm{H}, J=16 \mathrm{~Hz}, \mathrm{CH}=\mathrm{CH}),{ }^{13} \mathrm{C} \mathrm{NMR}(100$ $\left.\mathrm{MHz}, \mathrm{DMSO}-d_{6}\right) \delta(\mathrm{ppm}): 168.91(\mathrm{C}=\mathrm{O}), 144.45$ $(\mathrm{C}=\mathrm{N}), 150.01(\mathrm{C}=\mathrm{N}), 144.56,144.25,134.44$, $134.60,134.39,131.28,130.74,129.41,119.59$ (Ar-C and ethene C).

N'-(1-phenylethylidene)isonicotinohydrazide (9) [16]

A mixture of compound 1 (10 mol) and acetophenone $(10 \mathrm{~mol})$ in ethanol were refluxed for 5 hrs. The precipitate obtained was filtered off, washed and recrystallized from ethanol to give compound 9 as pale yellow crystals. Yield 90\%, m.p. $182-185^{\circ} \mathrm{C}$.

5-Methyl-5-phenyl-2-thioxo-1,3,4-thiadiazolidin3-yl)(pyridin-4-yl)methanone (10)

A mixture of compound 9 (1 mmol), carbon disulfide (1 mmol) and $\mathrm{KOH}(1 \mathrm{mmol})$ was boiled under reflux for $1 \mathrm{hr}$ the content of the flask, and then acidified by dilute acetic acid $(20 \mathrm{~mL}, 1: 10)$ orange powder of compound $\mathbf{1 0}$ was obtained after recrystallization from of ethanol. Yield $62 \%$, m.p. $159-160{ }^{\circ} \mathrm{C}$. Elem. Anal. Calcd. (\%) for $\mathrm{C}_{15} \mathrm{H}_{13} \mathrm{~N}_{3} \mathrm{OS}_{2}$ (315.41): C, 57.12; H, 4.15; N, 13.32; S, 20.33. Found: C, 57.3; H, 4.2; N, 13.4; $\mathrm{S}, 20.4$. IR (KBr, v, $\left.\mathrm{cm}^{-1}\right)$ : $1646(\mathrm{C}=\mathrm{O}), 1282$ $(\mathrm{C}=\mathrm{S}) .{ }^{1} \mathrm{HNMR}\left(400 \mathrm{MHz}, \mathrm{DMSO}-d_{6}\right) \delta(\mathrm{ppm})$ :
11.02 (s, 1H, NH), 8.81-8.79 (d, 2H, $J=6 \mathrm{~Hz}, \mathrm{CH}$ of $\mathrm{C}_{2}$ and $\mathrm{C}_{6}$ of pyridine ring), 8.77-8.76 (d, $2 \mathrm{H}$, $J=6 \mathrm{~Hz}, \mathrm{CH}$ of $\mathrm{C}_{3}$ and $\mathrm{C}_{5}$ of pyridine ring), 7.91$7.35\left(\mathrm{~m}, 5 \mathrm{H}, \mathrm{CH}\right.$ of phenyl ring), $2.27\left(\mathrm{~s}, 3 \mathrm{H}, \mathrm{CH}_{3}\right.$ out of the plane), $2.38\left(\mathrm{~s}, 3 \mathrm{H}, \mathrm{CH}_{3}\right.$ in the plane).

5-(Pyridin-4-yl)-3H-1,2,4-triazole-3-thione (11)

A solution of compound $\mathbf{1}(0.01 \mathrm{~mol})$ and ammonium thiocyanate $(0.01 \mathrm{~mol})$ in acetic acid was heated under reflux for $2 \mathrm{hr}$, the content of the flask was poured on $\mathrm{NaHCO}_{3} / \mathrm{H}_{2} \mathrm{O}(1: 10)$, concentrated and left at room temperature overnight to give a white powder of compound 11, that was filtered, dried and recrystallized from acetic acid. Yield $45 \%$, m.p. $338-340^{\circ} \mathrm{C}$. Elem. Anal. Calcd. (\%) for $\mathrm{C}_{7} \mathrm{H}_{4} \mathrm{~N}_{4} \mathrm{~S}$ (176.20): C, 47.72; H, 2.29; N, 31.80; S, 18.20. Found: C, 47.8; H, 2.3; $\mathrm{N}, 31.9 ; \mathrm{S}, 18.3$. IR (KBr, v, $\left.\mathrm{cm}^{-1}\right): 1666(\mathrm{C}=\mathrm{N})$, $1302(\mathrm{C}=\mathrm{S}) .{ }^{1} \mathrm{H}$ NMR $\left(400 \mathrm{MHz}, \mathrm{DMSO}-d_{6}\right) \delta$ (ppm): 8.73-8.72 (d, $2 \mathrm{H}, J=5.6 \mathrm{~Hz}, \mathrm{CH}$ of $\mathrm{C}_{2}$ and $\mathrm{C}_{6}$ of pyridine ring), 7.81-7.80 (d, $2 \mathrm{H}, J=5.6 \mathrm{~Hz}$, $\mathrm{CH}$ of $\mathrm{C}_{3}$ and $\mathrm{C}_{5}$ of pyridine ring), 18.3. MS: $\mathrm{m} / \mathrm{z}$ : $176\left(\mathrm{M}^{+}, 5 \%\right), 51(100 \%)$.

\section{N'-cyclohexylidenebenzohydrazide (12) [17]}

A mixture of compound 1 (1 mmol) and cyclohexanone $(1 \mathrm{mmol})$ in ethanol were refluxed for $5 \mathrm{hrs}$. The reaction mixture was concentrated and left at room temperature. The crude product obtained on re-crystallization from alcohol to give the hydrazone of isonicotinic acid as yellow powder 12 . Yield $60 \%$, m.p. $180-182^{\circ} \mathrm{C}$.

(3-Phenyl-5-thioxo-4,5-dihydro-1H-1,2,4-triazol1-yl)(pyridin-4-yl)methanone (13a)

A mixture of compound 12 ( $1 \mathrm{mmol})$, benzoyl isothiocyanate $(1 \mathrm{mmol})$ in acetone was heated under reflux for $1 \mathrm{hr}$, then keep at refrigerator overnight and then the mixture was filtered off and recrystallized from ethanol to give a white powder of compounds 13a. Yield 51\%, m.p. 278$280{ }^{\circ} \mathrm{C}$. Elem. Anal. Calcd. (\%) for $\mathrm{C}_{14} \mathrm{H}_{12} \mathrm{~N}_{4} \mathrm{OS}$ (284.34): C, 59.14; H, 4.25; N, 19.70; S, 11.28 . Found: C, 59.2; H, 4.35; N, 19.80; S, 11.38. IR $\left(\mathrm{KBr}, v, \mathrm{~cm}^{-1}\right): 3204(\mathrm{NH}), 1668(\mathrm{C}=\mathrm{O}), 1217$ $(\mathrm{C}=\mathrm{S}) .{ }^{1} \mathrm{H}$ NMR $\left(400 \mathrm{MHz}, \mathrm{DMSO}-d_{6}\right) \delta(\mathrm{ppm})$ : 12.32 (s, 1H, SH), 11.81 (s, 1H, NH), 8.81-8.80 (d, $2 \mathrm{H}, J=2 \mathrm{~Hz}, \mathrm{CH}$ of $\mathrm{C}_{2}$ and $\mathrm{C}_{6}$ of pyridine ring), 8.79-8.78 (d, 2H, J =2 Hz, $\mathrm{CH}$ of $\mathrm{C}_{3}$ and $\mathrm{C}_{5}$ of pyridine ring), $8.00-7.53(\mathrm{~m}, 5 \mathrm{H}, \mathrm{CH}$ of phenyl ring). ${ }^{13} \mathrm{C}$ NMR (100 MHz, DMSO- $\left.d_{6}\right)$ $\delta$ (ppm): $162.56(\mathrm{C}=\mathrm{S}), 157.94(\mathrm{C}=\mathrm{O}), 149.94$ $(\mathrm{C}=\mathrm{N}), 149.74,138.12,135.00,130.71,128.14$, $127.19,119.70$ (Ar-C). 
Pyridin-4-yl(3-styryl-5-thioxo-2,5-dihydro- $1 \mathrm{H}$ 1,2,4-triazol-1-yl)methanone (13b)

This compound was prepared by the same method used in the synthesis of 13a by using cinnamoylisothiocyanate instead of benzoyl isothiocyanate. Yield $51 \%$, m.p. $327-330^{\circ} \mathrm{C}$. Elem. Anal. Calcd. (\%) for $\mathrm{C}_{16} \mathrm{H}_{12} \mathrm{~N}_{4} \mathrm{OS}$ (308.36): $\mathrm{C}$, 62.32; H, 3.92; N, 18.17; S, 10.40. found: C, 62.4; $\mathrm{H}, 4 ; \mathrm{N}, 18.2 ; \mathrm{S}, 11 . \mathrm{IR}\left(\mathrm{KBr}, \mathrm{v}, \mathrm{cm}^{-1}\right): 3463(\mathrm{NH})$, $1687(\mathrm{C}=\mathrm{O}) .{ }^{1} \mathrm{H}$ NMR (400 MHz, DMSO- $d$ ) $\delta$ (ppm): $13.09(\mathrm{~s}, 1 \mathrm{H}, \mathrm{NH}), 8.75-8.74(\mathrm{~d}, 1 \mathrm{H}$, $\mathrm{CH}=\mathrm{CH}), 7.95-7.48(\mathrm{~m}, 9 \mathrm{H}, \mathrm{CH}$ of phenyl ring, $\mathrm{CH}$ of pyridine ring), 6.99-6.95 (d, $1 \mathrm{H}, \mathrm{CH}=\mathrm{CH})$. ${ }^{13} \mathrm{C}$ NMR $\left(100 \mathrm{MHz}\right.$, DMSO- $\left.d_{6}\right) \delta(\mathrm{ppm}): 163.55$ $(\mathrm{C}=\mathrm{S}), \quad 159.95 \quad(\mathrm{C}=\mathrm{O}), \quad 159.87(\mathrm{C}=\mathrm{N}), 150.74$, $137.12,134.00,134.60,130.71,129.14,128.19$, 120.70, 118.77 (Ar-C and ethene-C).

\section{Antimicrobial activity}

The Susceptibility tests were performed according to the National Committee for Clinical Laboratory Standards (NCCLS) recommendations. Screening tests regarding the inhibition zone were carried out by the agar-well diffusion method [18]. The inoculum suspension was prepared from colonies grown overnight on an agar plate and inoculated into Mueller-Hinton broth (fungi using malt broth). A sterile swab was immersed in the suspension and used to inoculate Mueller-Hinton agar plates (fungi using malt agar plates). Six millimeter $(6.0 \mathrm{~mm})$ diameter wells were cut from the agar using a sterile cork-borer, and then $0.05 \mathrm{ml}$ of concentration $(5 \mathrm{mg} / 1 \mathrm{~mL})$ of different tested compounds was transferred into each well. The inhibition zone was measured around each well after $24 \mathrm{~h}$ at $37^{\circ} \mathrm{C}$. Antimicrobial activity was evaluated by measuring the mean zone of inhibition against the test organism. Gentamycin and Ketoconazole were used as standard drugs. Dimethyl sulfoxide used as solvent controls.

\section{Results and Discussion}

\section{Chemistry}

$N$-(2-isonicotinoylhydrazinecarbonothioyl) cinnamamide [19] (3) was obtained by the reaction of isonicotinic acid hydrazide (1) (isoniazid) with cinnamoyl isothiocyanate (2) (prepared through reaction of cinnamoyl chloride with ammonium thiocyanate in dioxane) [20] via michael addition followed by hydrogen transfer and subsequent 1,3$\mathrm{H}$ shift as depicted in the following mechanism (Scheme 1). The ${ }^{1} \mathrm{H}$ NMR spectrum of compound 3 showed a deshielded broad signal due to $-\mathrm{SH}$ group at $13.626 \mathrm{ppm}\left(\mathrm{D}_{2} \mathrm{O}\right.$-exchangeable). It is interesting to note that thiocarbonyl compound is present in their thion-thiol tautomeric form solution as indicated by IR and ${ }^{1} \mathrm{H}$ NMR spectra. $\mathrm{D}_{2} \mathrm{O}$-exchangeable $\mathrm{NH}$ signals were observed at $12.264 \mathrm{ppm}, 11.761 \mathrm{ppm}$ and $11.429 \mathrm{ppm}$ in different electronic density. The downfield vinyl proton was shown at $\delta=8.808 \mathrm{ppm}$ with $J=16$ Hz. The multiplet signal at $\delta=7.479-8.796 \mathrm{ppm}$ was assigned to aromatic and pyridine protons. The second trans vinyl proton was resonated at $\delta$ $=7.089 \mathrm{ppm}$ with $J=16 \mathrm{~Hz}$. The IR spectrum of compound 3 displayed signals for $\mathrm{NH}, \mathrm{SH}, 2 \mathrm{C}=\mathrm{O}$ and $\mathrm{C}=\mathrm{N}$ at $3194,2653,1686,1668$ and $1631 \mathrm{~cm}^{-1}$.

The pyrimidine 4 was obtained from cyclization of cinnamoyl thiosemicarbazide 3 by heating with lead acetate in acetic acid as shown in Scheme 2. ${ }^{1} \mathrm{H}$ NMR was in agreement with the pyrimidine structure which showed two $\mathrm{NH}$ signals at $12.01 \mathrm{ppm}$ and $12.00 \mathrm{ppm}$ (controlled by changing $\mathrm{D}_{2} \mathrm{O}$ ) in addition to the aromatic protons. IR spectrum showed two carbonyls

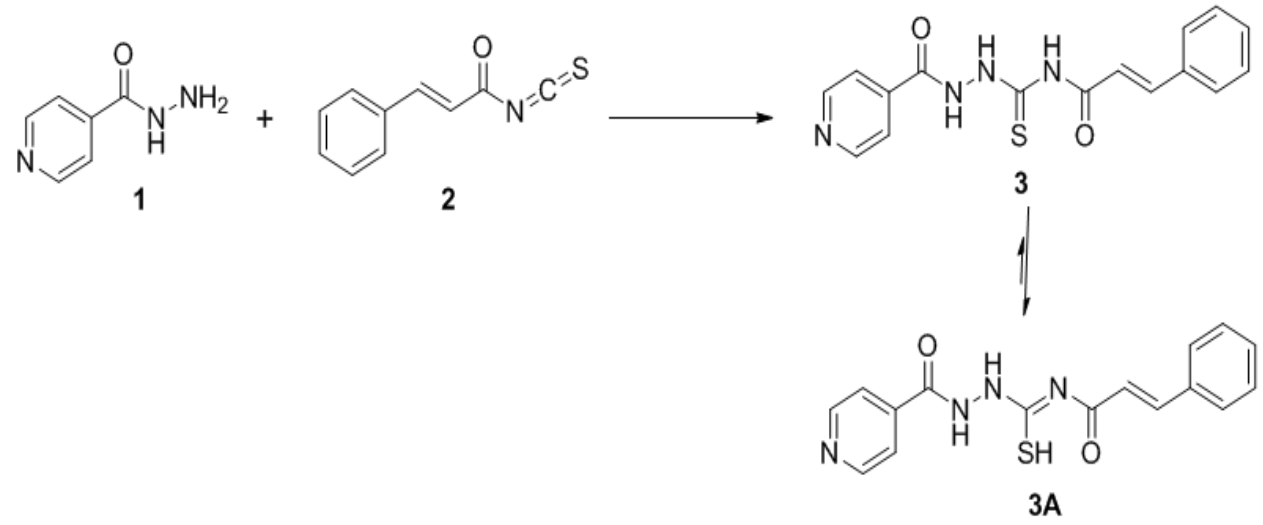

Scheme1. Synthesis of N-(2-isonicotinoylhydrazine-1-carbonothioyl) cinnamamide (3). 
stretching frequency at 1689 and $1634 \mathrm{~cm}^{-1}$ in addition to $\mathrm{C}=\mathrm{S}$ function at $1217 \mathrm{~cm}^{-1} .{ }^{13} \mathrm{C} \mathrm{NMR}$ of compound 4 showed signals at 172.06, 163.64 and $160 \mathrm{ppm}$ of the carbons of $\mathrm{C}=\mathrm{S}$ and $2 \mathrm{C}=\mathrm{O}$ $\mathrm{sp}^{2}$ carbon. The cyclization reaction of compound 3 using sodium ethoxide was also studied. Thus, heating of thiosemicarbazide with sodium ethoxide furnished triazolothiazine $\mathbf{5}$ through thiazine cyclization followed by cyclocondensation and subsequent dehydration as demonstrated in Scheme 2. ${ }^{1} \mathrm{H}$ NMR of condensed compound 5 revealed no NH signals. Aromatic hydrogens were observed as a multiplet signal at 8.53-6.47 ppm. ${ }^{13} \mathrm{C}$ NMR of compound $\mathbf{5}$ showed signals at 172 and $169 \mathrm{ppm}$ due to the $\mathrm{C}=\mathrm{O}$ and $\mathrm{C}=\mathrm{N} \mathrm{sp}{ }^{2}$ carbons. The 1,3,4- thiadiazole derivative 6 was obtained as a result of treatment of compound 3 by $\mathrm{H}_{2} \mathrm{SO}_{4}$ via an attack of $\mathrm{SH}$ nucleophilc to the electrophilic carbonyl carbon of nictonyl moiety followed by dehydration as shown in Scheme 2. ${ }^{1} \mathrm{H}$ NMR detected the triazole structure by the presence of $\mathrm{D}_{2} \mathrm{O}$-exchangeable $\mathrm{NH}$ signal at 11.94 ppm and also the appearance of $\mathrm{C}=\mathrm{O}$ function in IR spectrum at $1689 \mathrm{~cm}^{-1}$ potentiates the suggested structure. $\mathrm{In}^{13} \mathrm{C}$ NMR of compound 6 the $\mathrm{C}=\mathrm{O}$,
$\mathrm{C}=\mathrm{S}$ and $\mathrm{C}=\mathrm{N} \mathrm{SP}^{2}$ carbon showed signals at 163 ppm, $159.9 \mathrm{ppm}$ and $159.8 \mathrm{ppm}$.

Acylation of cinnamoyl thiosemicarbazide 3 with chloroacetyl chloride in presence of sodium acetate formed thiazole derivative 7 . The reaction may proceed via the formation of the anion $\mathbf{A}$ of the more acidic NH followed by chloroacetylation and subsequent enolization forming the final product 7 as depicted in Scheme 3. The IR spectrum of compound 7 showed the characteristic broad band of the hydroxyl group at $3394 \mathrm{~cm}^{-1}$ also displayed two different carbonyls at 1683 and $1627 \mathrm{~cm}^{-1}$. The ${ }^{1} \mathrm{H}$ NMR spectrum of thiazole derivative 7 revealed two downfield signals at 13.17 and $12.93 \mathrm{ppm}$ for $\mathrm{OH}$ and $\mathrm{NH}$ protons $\left(\mathrm{D}_{2} \mathrm{O}\right.$-exchangeable). The deshielded vinyl proton resonated at $\delta=$ $7.866 \mathrm{ppm}$ with $J=15 \mathrm{~Hz}$, aromatic protons appeared at 7.031-8.062 ppm as a multiplet singnal and the other vinylic proton located at $\delta=6.989 \mathrm{ppm}$ with $J=15 \mathrm{~Hz}$ as doublet. The thiazole proton was observed at $\delta=5.183 \mathrm{ppm}$ as a singlet signal. Moreover, $2 \mathrm{C}=\mathrm{O}$ and $\mathrm{C}=\mathrm{N}$ groups resonated at 164.19 , and $160.88 \mathrm{ppm}$

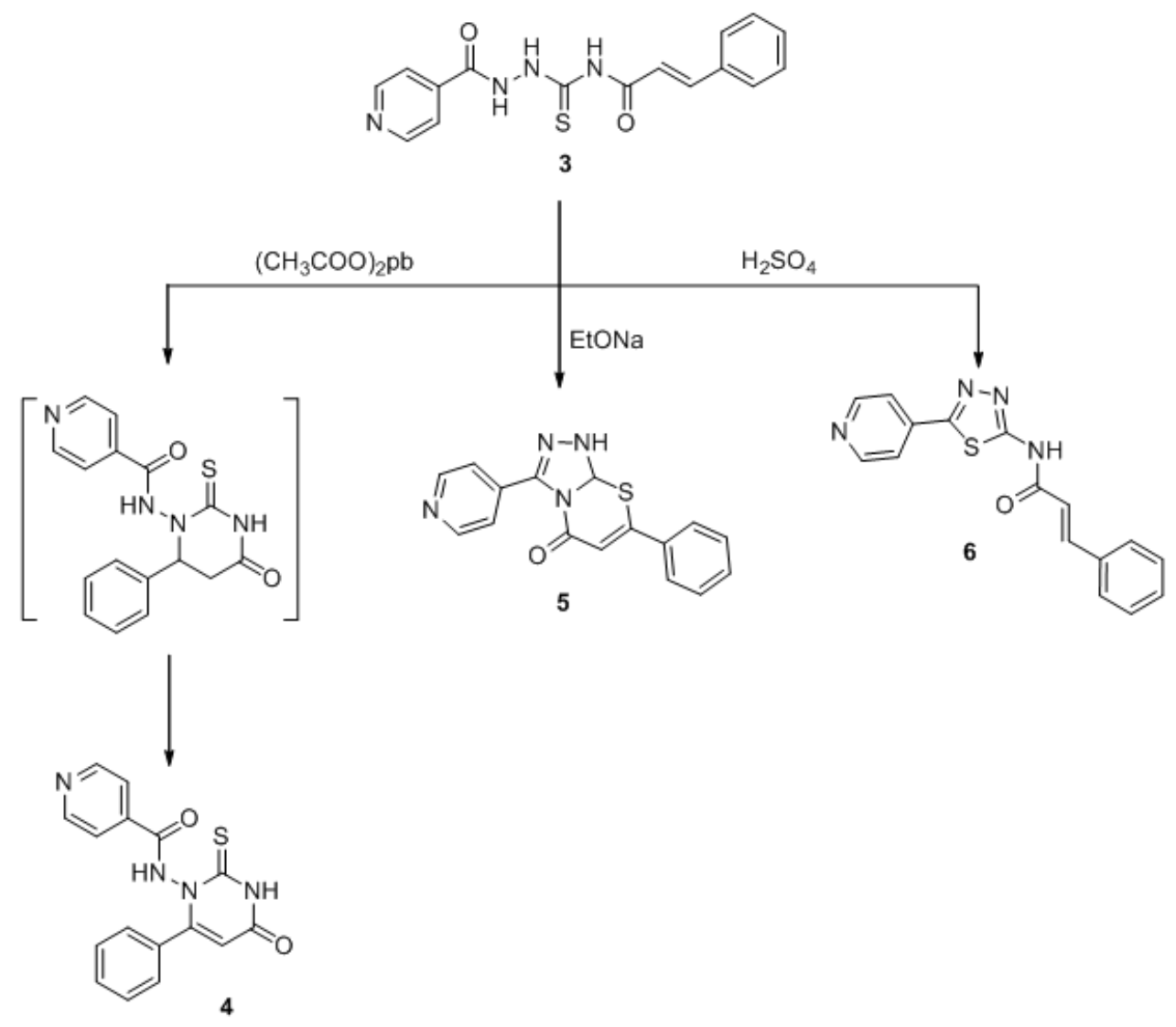

Scheme 2. Synthesis of pyrimidine 4, triazolothiazine 5 and 1,3,4-thiadiazole 6 . 
in the ${ }^{13} \mathrm{C}$ NMR spectrum of compound 7. The reaction of thiosemicarbazide derivative $\mathbf{3}$ with sodium hypochlorite in the presence of $\mathrm{NH}_{4} \mathrm{OH}$ and $\mathrm{NaOH}$ resulted in thiadiazole cyclization affording compound $\mathbf{8}$ as shown in Scheme $\mathbf{3}$ via the formation of the non-isolable sulphenyl chloride, amination forming sulphenamide which in turn undergo intramolecular cyclodehydration [21]. All spectral data are consistent with the title thiadiazole derivative 8 . Thus ${ }^{1} \mathrm{H}$ NMR revealed broad signal at 12.41 for two acidic NH signals ( $\mathrm{D}_{2} \mathrm{O}$-exchangeable). Two doublets signals at $6.557 \mathrm{ppm}(J=16 \mathrm{~Hz})$ and $7.617(J=16 \mathrm{~Hz})$ ppm are assigned to vinyl protons indicating that the ethylene in the styryl moiety is in transconformation in the compound $\mathbf{8}$. In addition, a multiplet signal was observed at 7.432-7.416 ppm due to aromatic protons. IR spectrum of compound 8 revealed the presence of bands for $\mathrm{NH}$ at $3055 \mathrm{~cm}^{-1}$, for $\mathrm{C}=\mathrm{O}$ at $1685 \mathrm{~cm}^{-1}$, at 1631 $\mathrm{cm}^{-1}$ due to $\mathrm{C}=\mathrm{N} \mathrm{cm}{ }^{-1}$ and $1577 \mathrm{~cm}^{-1} \mathrm{C}=\mathrm{C} \cdot{ }^{13} \mathrm{C}$ NMR of compound $\mathbf{1 0}$ showed signals at 168.09 and 144.4 ppm of $\mathrm{C}=\mathrm{O}$ and $\mathrm{C}=\mathrm{N} \mathrm{sp}{ }^{2}$ carbons.

Cyclization of Schiff base 9 was achieved upon the treatment of compound $\mathbf{9}$ with carbon disulfide and $\mathrm{KOH}$ to afford thiadiazolothione $\mathbf{1 0}$ as shown in Scheme 4. ${ }^{1} \mathrm{H}$ NMR of $\mathbf{1 0}$ showed a downfield signal at $11.020 \mathrm{ppm}$ for $\mathrm{NH}$ (controlled by changing $\mathrm{D}_{2} \mathrm{O}$ ) in addition to aromatic and pyridine protons which observed as a multiplet at 8.807-7.349 ppm. Also, the ${ }^{1} \mathrm{H}$ NMR spectrum of $\mathbf{1 0}$ revealed two signals for $\mathrm{CH}_{3}$ at 2.274 and 2.384 ppm. IR spectrum of $\mathbf{1 0}$ showed $\mathrm{C}=\mathrm{O}$ band at 1646 $\mathrm{cm}^{-1}$ and $\mathrm{C}=\mathrm{S}$ at $1282 \mathrm{~cm}^{-1}$. Upon addition of hydrazide 1 to ammonium thiocyanate furnished triazolothione $\mathbf{1 1}$ in one step through thiosemicarbazide by $\mathrm{N}$-cyclization followed by oxidation as illustrated in Scheme $4 .{ }^{1} \mathrm{H}$ NMR showed only the pyridine protons. IR also showed $\mathrm{C}=\mathrm{N}$ band at $1666 \mathrm{~cm}^{-1}$ and $\mathrm{C}=\mathrm{S}$ at $1302 \mathrm{~cm}^{-1}$. The mass spectrum of 11 showed a peak at $m / z 176\left(\mathrm{M}^{+}\right)$corresponding to its molecular ion.

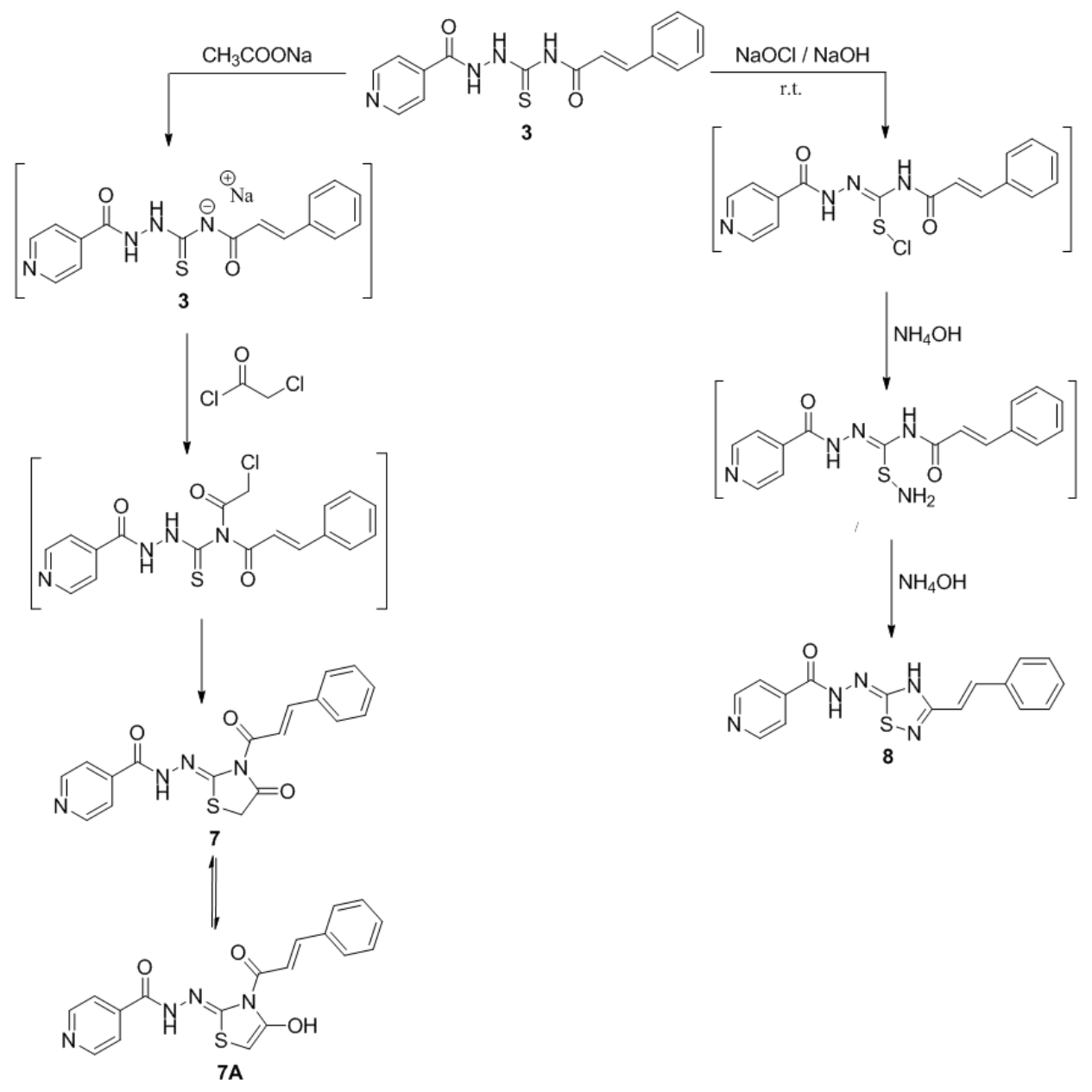

Scheme 3. Synthesis of 1,3-thiazole 7 and 1,2,4-thiadiazole 8. 


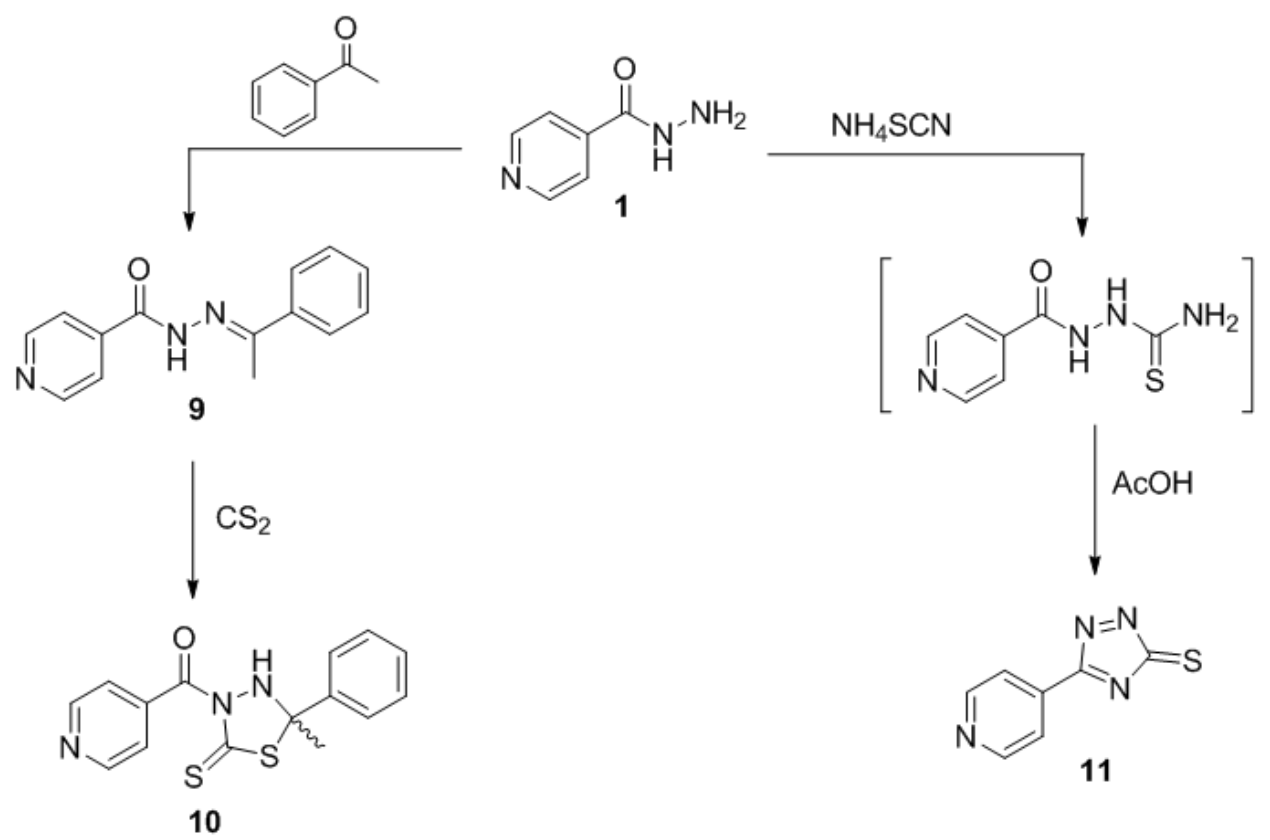

Scheme 4. Synthesis of 1,3,4-thiadiazole 10 and 1,3,4-triazole 11.

The hydrazone $\mathbf{1 2}$ was reacted with arylisothiocyanates $(\mathrm{Ar}=\mathrm{Ph}, \mathrm{PhCH}=\mathrm{CH})$ to give triazolothione $\mathbf{1 3} \mathbf{a}$ and $\mathbf{1 3 b}$. The reaction may be preceded through the formation of thiosemicarbazone followed by cyclodehydration and subsequent enaminc hydrolysis [22, 23] as illustrated in Scheme 5. ${ }^{1} \mathrm{H}$ NMR spectrum of 13a showed downfield signal at $12.324 \mathrm{ppm}$ for $\mathrm{SH}$ and $11.439 \mathrm{ppm}$ for $\mathrm{NH}$ (controlled by changing $\mathrm{D}_{2} \mathrm{O}$ ) that indicate the compound 13a present in thion-thiol tautameric form. Also, the $\mathrm{C}=\mathrm{O}$ absorption stretching was observed in IR spectrum at $1668 \mathrm{~cm}^{-1} .{ }^{1} \mathrm{H}$ NMR spectrum of $\mathbf{1 3 b}$ showed downfield deshielded signal at 13.3089 ppm for $\mathrm{NH}$ (controlled by changing $\mathrm{D}_{2} \mathrm{O}$ ) due to intra-molecular hydrogen bond. Also, the $\mathrm{C}=\mathrm{O}$ absorption stretching was observed in IR spectrum at $1687 \mathrm{~cm}^{-1} \cdot{ }^{13} \mathrm{C}$ NMR spectra of compound 13a and $\mathbf{1 3 b}$ are given in the experimental section.<smiles>O=C(NN=C1CCCCC1)c1ccncc1</smiles>

12<smiles>O=C(Br)N=C=S</smiles>

2a, b a, $\mathrm{Ar}=\mathrm{Ph}$

b, $\mathrm{Ar}=\mathrm{Ph}-\mathrm{CH}=\mathrm{CH}-$<smiles>C=C[Al]c1nc(S)n(C(=O)c2ccncc2)n1</smiles>

$13 a$<smiles>O=C(c1ccncc1)n1[nH]c([AlH2])nc1=S</smiles>

13a, b<smiles>O=C(NC(=S)N(N=C1CCCCC1)C(=O)c1ccncc1)C1CCCCC1</smiles><smiles>O=C(c1ccncc1)n1c([Al])nc(=S)n1C1=CCCCC1</smiles>

Scheme 5. Synthesis of 1,3,4-triazoles 13a, b. 
Antimicrobial activity

All bacterial and fungi strains were obtained from the Regional Center for Mycology and Biotechnology, AL-Azhar University (Cairo, Egypt) and were as follows: Escherichia coli ATCC 25955, Salmonella typhimurium ATCC14028, Staphylococcus aureus (RCMB010010), Bacillus subtilies NRRLB-543, Aspergillus falvus
(RCMB002002) and Candida albicans ATCC 10231. All the newly synthesized compounds were dissolved in dimethyl sulfoxide (DMSO) to prepare final concentration $5 \mathrm{mg} / 1 \mathrm{~mL}$. The antimicrobial activity results are summarized in Table 1. The synthesized compounds showed weak to moderate anti-microbial activity.

TABLE 1. Screening for antimicrobial activity of synthesized compounds

\begin{tabular}{clllllll}
\hline \multirow{2}{*}{$\begin{array}{c}\text { Compound } \\
\text { number }\end{array}$} & \multicolumn{5}{c}{ Mean inhibition zone (M. IZ mm) } & and \pm Standard deviation (S.D.) \\
\cline { 2 - 7 } & \multicolumn{5}{c}{ Gracteria strains $+v e$} & \multicolumn{4}{c}{ Gram Fungi strains } \\
& S. aureus & B. s. & Sal. t. & E.coli & A.falvus & C.albicans \\
\hline $\mathbf{3}$ & - & - & - & - & - & - \\
$\mathbf{4}$ & $10 \pm 0.2$ & - & $11 \pm 0.1$ & - & $12 \pm 0.1$ & $15 \pm 0.7$ \\
$\mathbf{5}$ & - & - & $9 \pm 0.2$ & - & $12 \pm 0.2$ & - \\
$\mathbf{6}$ & - & - & $8 \pm 0.4$ & - & - & - \\
$\mathbf{7}$ & $6 \pm 0.2$ & - & $7 \pm 0.3$ & - & - & $14 \pm 0.6$ \\
$\mathbf{8}$ & $11 \pm 0.1$ & - & - & - & $10 \pm 0.2$ & - \\
$\mathbf{1 0}$ & - & $16 \pm 0.6$ & $14 \pm 0.6$ & - & $15 \pm 0.6$ & $12 \pm 0.4$ \\
$\mathbf{1 1}$ & - & - & - & - & - & - \\
$\mathbf{1 3 a}$ & $14 \pm 0.4$ & - & - & - & - & - \\
$\mathbf{1 3 b}$ & $13 \pm 0.3$ & - & $12 \pm 0.5$ & - & - & - \\
Gentamycin & $23 \pm 0.01$ & $16 \pm 0.02$ & $27 \pm 0.01$ & $33 \pm 0.01$ & - & - \\
Ketoconazole & - & - & - & - & $26 \pm 0.01$ & $30 \pm 0.01$ \\
\hline
\end{tabular}

$(-)=$ No activity. S. aureus $=$ Staphylococcus aureus, B. $\boldsymbol{s} .=$ Bacillus subtilies, Sal. t. $=$ Salmonella typhimurium, E. coli= Escherichia coli. A. falvus =Aspergillus falvus, C. albicans. $=$ Candida albicans.

\section{Conclusions}

This study reports the synthesis of some heterocyclic compounds containing triazolothiazine, 1,2,4-thiadiazole, 1,2,4-triazolethione and dihydropyrimidine rings. Spectral and analytical data of the newly synthesized compounds were in good agreement with proposed chemical structure. The antimicrobial activity study revealed that compounds $\mathbf{4}, \mathbf{5}, \mathbf{6}$, 7, 8, 10, 13a and 13b showed moderate activity except compounds $\mathbf{3}$ and $\mathbf{1 1 .}$

\section{$\underline{\text { References }}$}

1. Matei, L., Bleotu, C., Baciu, I., Draghici, C., Ionita, P., Paun and A. Zarafu, I., Synthesis and bio evaluation of some new isoniazid derivatives. Bioorganic \& Medicinal Chemistry, 21(17), 5355-5361 (2013).

2. Zumla, A., Chakaya, J., Centis, R., D’Ambrosio, L., Mwaba, P., Bates, M., and Mfinanga, S. Tuberculosis treatment and management-an update on treatment regimens, trials, new drugs, and adjunct therapies. The Lancet Respiratory Medicine, 3(3), 220-234(2015).

3. Martins, F., Santos, S., Ventura, C., Elvas-Leitão, R., Santos, L., Vitorino, S.and Aires-de-Sousa, J. Design, synthesis and biological evaluation of novel isoniazid derivatives with potent antitubercular activity. European Journal of Medicinal Chemistry, 81, 119-138 (2014).

4. Dos Santos Fernandes, G.F., deSouza, P.C., Marino, L.B., Chegaev, K., Guglielmo, S., Lazzarato, L. and Dos Santos, J.L. Synthesis and biological activity of furoxan derivatives against Mycobacterium tuberculosis. European Journal of Medicinal Chemistry, 123, 523-531 (2016).

5. World Health Organization, Global Tuberculosis Report 2017. Geneva: World Health Organization (2017).

6. Chetty, S., Ramesh, M., Singh-Pillay, A., and Soliman, M. E.. Recent advancements in the development of anti-tuberculosis drugs. Bioorganic \& Medicinal Chemistry Letters, 27(3), 
370-386 (2017).

7. Dharra, R. and P. Mehta, Mycobacterial Diseases. (2018).

8. Demirbas, N., Karaoglu, S. A., Demirbas, A., and Sancak, K. Synthesis and antimicrobial activities of some new 1-(5-phenylamino-[1, 3, 4] thiadiazol-2-yl) methyl-5-oxo-[1, 2, 4] triazole and 1-(4-phenyl-5-thioxo-[1, 2, 4] triazol-3yl) methyl-5-oxo-[1, 2, 4] triazole derivatives. European Journal of Medicinal Chemistry, 39(9), 793-804 (2004).

9. Bayrak, H., Demirbas, A., Karaoglu, S. A., and Demirbas, N. Synthesis of some new 1, 2, 4-triazoles, their Mannich and Schiff bases and evaluation of their antimicrobial activities. European Journal of Medicinal Chemistry, 44(3), 1057-1066 (2009).

10. Abdallah, A. E., Helal, M., and Elakabawy, N.I., Heterocyclization, Dyeing Applications and Anticancer Evaluations of Benzimidazole Derivatives: NovelSynthesis of Thiophene, Triazole and Pyrimidine Derivatives. Egyptian Journal of Chemistry, 58(6), 699-719 (2015).

11. El-Arab, E. E., El-Said, A., Amine, M., and Moharram, H.. Synthesis and Antitumor Activity Evaluation of New 2-(4-aminophenyl) benzothiazole /oxazole/imidazole Derivatives. Egyptian Journal of Chemistry, 59(6), 967-984 (2016).

12. Clemons, M., Coleman, R. E., and Verma, S. Aromatase inhibitors in the adjuvant setting: bringing the gold to a standard? Cancer treatment reviews, 30(4), 325-332 (2004).

13. Fahim, A.M., Farag, A., Yakout, E., Nawwar, G., and Ragab, E.. Synthesis, biological evaluation of 1, 3, 4-oxadiazole, triazole and uracil derivatives from poly (ethylene terephthalate) waste. Egypt. J. Chem, 59, 285-303 (2016).

14. Fahmy, A., Abdel-Hamid, H.A., and Megally, A.N., Uses of Isothiocyanate as Building Block in Syntheses of Triazole, Thiadiazole, Quinazoline, and Pyrimidine Systems of Agrochemical and Biological Activities. Egyptian Journal of Chemistry, 58(6), 645-657(2015).
15. Khidre, R. E., Radini, I. A. M., and Abdel-Wahab, B. F. Synthesis of New Heterocycles Incorporating 3-(N-phthalimidomethyl)-1, 2, 4-triazole as Antimicrobial Agents. Egyptian Journal Of Chemistry, 59(5), 731-744 (2016).

16. Maccari, R., Ottana, R., Monforte, F., and Vigorita, M.G. In vitro antimycobacterial activities of 2'-monosubstituted isonicotinohydrazides and their cyanoborane adducts. Antimicrobial Agents and Chemotherapy, 46 (2), 294-299 (2002).

17. Hearn, M. J., Cynamon, M. H., Chen, M. F., Coppins, R., Davis, J., Kang, H. J.-O.and Trombino, D. Preparation and antitubercular activities in vitro and in vivo of novel Schiff bases of isoniazid. European Journal of Medicinal Chemistry, 44 (10), 4169-4178 (2009).

18. Hindler, J., Howard, B., and Keiser, J. Antimicrobial agents and antimicrobial susceptibility testing. Howard BJ. Clinical and Pathogenic Microbiology. 2nd ed. St. Louis: Mosby. (1994).

19. Chang, Y. T. C. et al. (1962) Vol. 8; (1962); p. 37,38-39; ; Vol. 58; nb. 13937; . Kexue Tongbao (Chinese Edition). (1963).

20. Assy, M., Some reaction with ethyl 2-aryl-4mercapto-6-methylpyrimidine-5-carboxylates. Sulfur Lett, 11, 75-82 (1990).

21. Sherif, M., Assy, M., Yousif, N., and Galahom, M.. Studies on heterocyclization of acetoacetanilide. Journal of the Iranian Chemical Society, 10(1), 85-91 (2013).

22. Villani Jr, F.J., Ethoxycarbonyl Isothiocyanate. Encyclopedia of Reagents for Organic Synthesis, (2001).

23. Stork, G., Brizzolara, A., Landesman, H., Szmuszkovicz, J., and Terrell, R.. The enamine alkylation and acylation of carbonyl compounds. Journal of the American Chemical Society, 85(2), 207-222 (1963).

(Received 12/7/2018; accepted 3/9/2018) 
الحولقه الغير متجانسه للايزونيكوتينك هيدارزيت :تخليق و تقييم النشاط البيولوجى

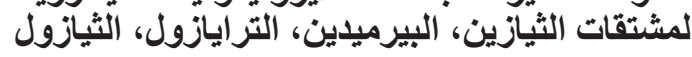

منى امام فرحان و محمد جمعه عاصى الزمي

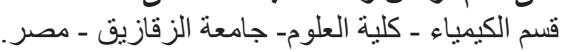

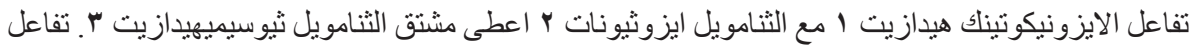

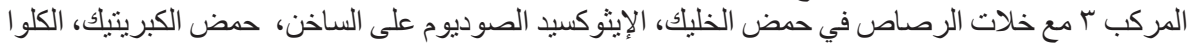

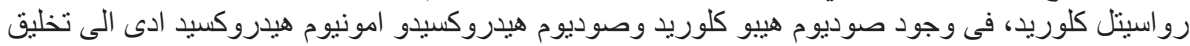

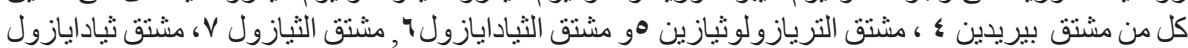

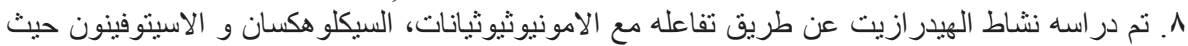

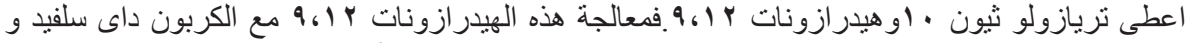

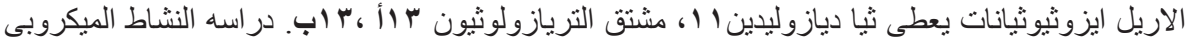

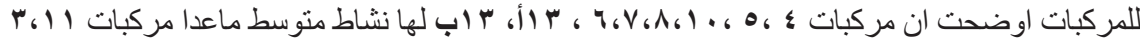

